\title{
Evaluation of Noncarious Cervical Lesions Restored with Resin-modified Glass Ionomer and Glass Carbomer: A Single- blind Randomized Controlled Clinical Trial
}

\author{
Jasmine J Rayapudi ${ }^{1}$, Ramarao Sathyanarayanan ${ }^{2}$, Usha Carounanidy ${ }^{3}$, Bindu M John ${ }^{4}$
}

\begin{abstract}
Aims and objectives: To compare and evaluate the clinical performance of glass carbomer cement over a period of 1 year, with that of resinmodified glass ionomer cement (RMGIC) in noncarious cervical lesions (NCCLs) in permanent teeth using the University of North Carolina (UNC)-modified United States Public Health Services (USPHS) criteria.

Materials and methods: Thirty-three subjects (30-60 years) with NCCLs of not $>2 \mathrm{~mm}$ depth in premolars were recruited. Fifty-six NCCLs were restored with RMGIC (group I) and another 56 NCCLs with glass carbomer (group II). Single-blind evaluation of clinical parameters was performed at baseline, 3rd, 6th, and 12th month using modified USPHS criteria. Intragroup comparison at various intervals was evaluated using the McNemar test and the intergroup comparison using Fisher's exact tests.

Results: Recall rate was $73.2 \%$ for 1 year. Statistically significant decline was present after 12 months for marginal integrity $(p=0.008)$, anatomic form (0.002), and color match ( $p=0.0003)$ for group II. Group I restorations showed better results in terms of retention, marginal integrity ( $p$ $=0.005)$, color match $(p<0.0001)$, wear $(p=0.0311)$, recurrent caries $(p=0.0228)$, marginal staining $(p=0.0086)$, fracture $(p=0.0054)$, and postoperative sensitivity $(p=0.0574)$.

Conclusion: Glass carbomer, despite containing nano-sized powder particles and thermal setting, falls short of demonstrating acceptable clinical performance.

Keywords: Fuji II LC, Glass carbomer, Glass ionomer cement, Heat cure, Randomized controlled clinical trial, Resin modified glass ionomer cement, Single-blind, United States Public Health Services criteria.

Journal of Scientific Dentistry (2021): 10.5005/jp-journals-10083-0940
\end{abstract}

\section{INTRODUCTION}

Resin-modified glass ionomer cement (RMGIC) introduced during 1989 overcame many inherent physical shortcomings of conventional GIC (cGIC). Adding light-cured resin particles to RMGIC ensued in increased early compressive plus flexural strength and improved resistance to initial moisture exchange and desiccation. Several clinical studies have demonstrated its longevity as a permanent restorative material. ${ }^{1,2}$ Recently, a new restorative material that shares the essential chemistry of GIC was developed with prerogatives of improved physical characteristics. Glass carbomer GCP glass fill is a fluorapatitecontaining cement with nano-sized powder particles which aid in remineralization and bonds to dentine and enamel. ${ }^{3}$ It can set in an autopolymerization mode, i.e., the aqueous acid reacts with the basic glass in a neutralization reaction. Nevertheless, the manufacturers endorse using a high-octane dental polymerization light $\left(1,400 \mathrm{~mW} / \mathrm{cm}^{2}\right)$ to accelerate this acid-base reaction. This is claimed to improve the marginal adaptation, increase bond strength, decrease porosity, increase compressive strength, and allow for shorter chair time. ${ }^{4-7}$

Few clinical trials have been done to equate the mechanical properties of glass carbomer cements with other restorative materials, but none compares the restorations in noncarious cervical lesions (NCCLs). Addressing this lacuna, we designed a study to compare the clinical working of glass carbomer cement with that of RMGIC (Fuji II LC) in NCCL restorations in permanent teeth over one year using the University of North Carolina
${ }^{1-4}$ Department of Conservative Dentistry and Endodontics, Indira Gandhi Institute of Dental Sciences, Sri Balaji Vidyapeeth, Puducherry, India

Corresponding Author: Jasmine J Rayapudi, Department of Conservative Dentistry and Endodontics, Indira Gandhi Institute of Dental Sciences, Sri Balaji Vidyapeeth, Puducherry, India, Phone: +91 8903553009, e-mail: jasmine.rayapudi@gmail.com

How to cite this article: Rayapudi JJ, Sathyanarayanan R, Carounanidy U, John BM. Evaluation of Noncarious Cervical Lesions Restored with Resin-modified Glass lonomer and Glass Carbomer: A Single-blind Randomized Controlled Clinical Trial. J Sci Dent 2021;11(1):8-15.

Source of support: Nil

Conflict of interest: None

(UNC)-modified United States Public Health Services (USPHS) criteria. The tested null hypothesis was that there would be no difference in the restorations done with Fuji II LC and those done with GCP carbomer techniques.

\section{Materials and Methods}

Following consent from the Institutional Review Board and the Institutional Ethical Committee, this study was chronicled with the Clinical Trials Registry of India (CTRI/2016/11/007497). All procedures executed were as per the ethical ideals of the national and institutional research committee and with the Helsinki declaration of 1975 and its subsequent amendments. 


\section{Patient Selection}

Patients amid the age group of 30--60 years were chosen based on the following inclusion conditions: good oral hygiene; the presence of at least two vital, nonmobile premolars having NCCLs not deeper than $2 \mathrm{~mm}$. Patients unable to return for recall appointments and those having irreversible pulpitis, fracture, or periodontitis were excluded. Informed consent was obtained from the patients in their language, i.e., Tamil.

\section{Sample Size Calculation}

The sample size was calculated as per results obtained from the study by Jyothi et al. where a similar comparison has been done between the clinical effects of using Giomer and RMGIC. ${ }^{8}$ The current study tested RMGIC and glass carbomer in two groups with each patient receiving both the restorations, namely:

Group I: RMGIC (GC Fuji II LC, GC Co. Ltd., Tokyo, Japan).

Group II: Glass carbomer (GCP Dental, Netherlands).

The formula used for the calculation to find the number of subjects $(N)$ in each of the two groups, for a constant difference in proportions $p_{1}$ and $p_{2}$ between the two groups across $n$ time points, was: ${ }^{9}$

$$
N=\frac{\left[z \alpha(2 \bar{p} q)^{21}+z \beta\left(p_{1} q_{1}+p_{2} q_{2}\right)^{2}\right]^{1^{2}}(1+(n-1) \rho)}{n\left(p_{1}-p_{2}\right)^{2}}
$$

Values used:

$p_{1}=0.8$ (for RMGIC-control); $p_{2}=0.5$ (for glass carbomer-test); rho $=0.6 n$ (time points) $=3$ (patient follows-up 3 times).

Alfa $=0.05, Z 0.05=1.96$; Beta $=0.2, Z 0.2=0.84, \alpha$ (allowable type I error) 0.05 (5\%), $\beta$ (allowable type II error) 0.20 (20\%) power of the study $(1-\beta)=80 \%$.

With these values, the sample size in each group was calculated as 56 (with an assumed 30\% drop-out rate).

\section{Randomization}

Each pair of selected premolars were randomly allocated to the two groups of RMGIC and glass carbomer using the lot system. Two lots were prepared. Each lot carried the side assigned to group I (RMGIC) or group II (glass carbomer). During the time of treatment, the patient could pick a lot manually in a random manner. Tooth to be intervened with RMGIC followed the tooth number mentioned in the lot. The other tooth was restored using glass carbomer. Hundred and twelve NCCLs were restored using the experimental design as shown in Flowchart 1. Flow diagram proposed by CONSORT for clinical trials is depicted in Flowchart 2. Particulars of the materials used in the intervention are specified in Table 1.

\section{Restorative Procedure}

Restorative treatments were performed by a single operator. All cavities were pumiced. To facilitate access and moisture control, a 212 Hu-Friedy cervical clamp and non-impregnated gingival retraction cord (\#0) was used to retract the gingival tissues and place the rubber dam. No mechanical retention or beveled enamel margins were given as GIC bonds chemically to the tooth structure. Adhesion to dentin was enhanced by surface conditioning with an aqueous solution of $10 \%$ polyacrylic acid for 20 seconds. ${ }^{10}$

Fuji II LC capsule was amalgamated in a vibrator for 10 seconds at $\sim 4,300 \mathrm{osc} /$ minute. The material was immediately extruded into the cavity and light-cured for 20 seconds using a visible light curing unit (Woodpecker Lux V Light Cure) at 1,200 mw/ $\mathrm{cm}^{2}$ according to the manufacturer's directives. Finishing, then polishing was done immediately after final setting with diamond polishing burs. A thin layer of nano-filled self-adhesive protective coating (G-Coat Plus) was light-cured onto the restoration. This liquid glaze prevents the initial sensitivity of GIC to water and ensures improved esthetics, surface smoothness, enhanced wear resistance, reduced risk of staining, and marginal protection. ${ }^{11}$

The glass carbomer capsule was mixed for 15 seconds at $\sim 4,300$ osc/minute. Soon after extruding the material directly into the cavity, a monomer-free silicone-based polysiloxane GCP gloss was applied onto the exterior of the restoration to protect against moisture and desiccation during curing. The restoration was heat-cured with a light cure device (GCP CarboLED CL-01) that has an output of $1,400 \mathrm{mw} / \mathrm{cm}^{2}$ for 60 seconds $\left(60^{\circ} \mathrm{C}\right) .{ }^{4}$ Use of heat accelerates the matrix-forming reaction of glass carbomer and leads to a shorter setting time. ${ }^{12}$ Finishing and polishing were done immediately after the final set with diamond polishing burs. GCP gloss was applied and cured again to provide an esthetic finish to the restoration. ${ }^{13}$ Intraoral digital images were collected at baseline and each recall appointment using a Canon 1300 DSLR camera with an EFS 18-55 MM Canon lens having a 1.53 magnification (Canon Inc., Melville, NY, USA). Figure 1 shows the representative photographs of clinical evaluation at each evaluated time period.

\section{Evaluation of the Outcomes}

Primary outcome measures were retention rate, marginal integrity, anatomic form, surface texture, color match, wear, marginal discoloration, recurrent caries, fracture, and postoperative sensitivity of the two materials.

Restorations were assessed soon after insertion, at 3 months, 6 months, and 1 year based on UNC-Modified USPHS criteria by a trained and calibrated evaluator who was blinded to the study. ${ }^{1,14-16}$

\section{Statistical Analysis}

Graph Pad Prism 6 computer software was used for statistical analysis. An intragroup comparison was done for all parameters at different time intervals with the McNemar test. Intergroup analysis for all parameters between the two groups was done using Fisher's exact test. With a confidence interval of $95 \%$, the level of significance was set at $p<0.05$.

\section{Results}

Fifty-six pairs of samples were recruited from 33 patients. The overall recall rate at 3 months was $80.4 \%$ and at 6 months and 1 year was $73.2 \%$. For detailed comparative analysis, the data were statistically analyzed for only 37 samples from 21 patients who reported for all the timed evaluations.

The research data are available on Mendeley Data [https://data. mendeley.com/datasets/3jm55gwcg4/1]. ${ }^{17}$ A summary of direct evaluations presenting data for all clinical parameters at baseline, 3 months, 6 months, and 1 year is shown in Table 2. Figure 2 represents the percentage of restorations that recorded Alfa at baseline, 3, 6, and 12 months for each parameter.

\section{Discussion}

Clinical performance of restorations is best assessed in Class-V evaluations because NCCLs have an unretentive cavity form with 
Flowchart 1: Experimental design

Presence of 2 premolar NCCL on either arch

Age 30-60

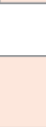
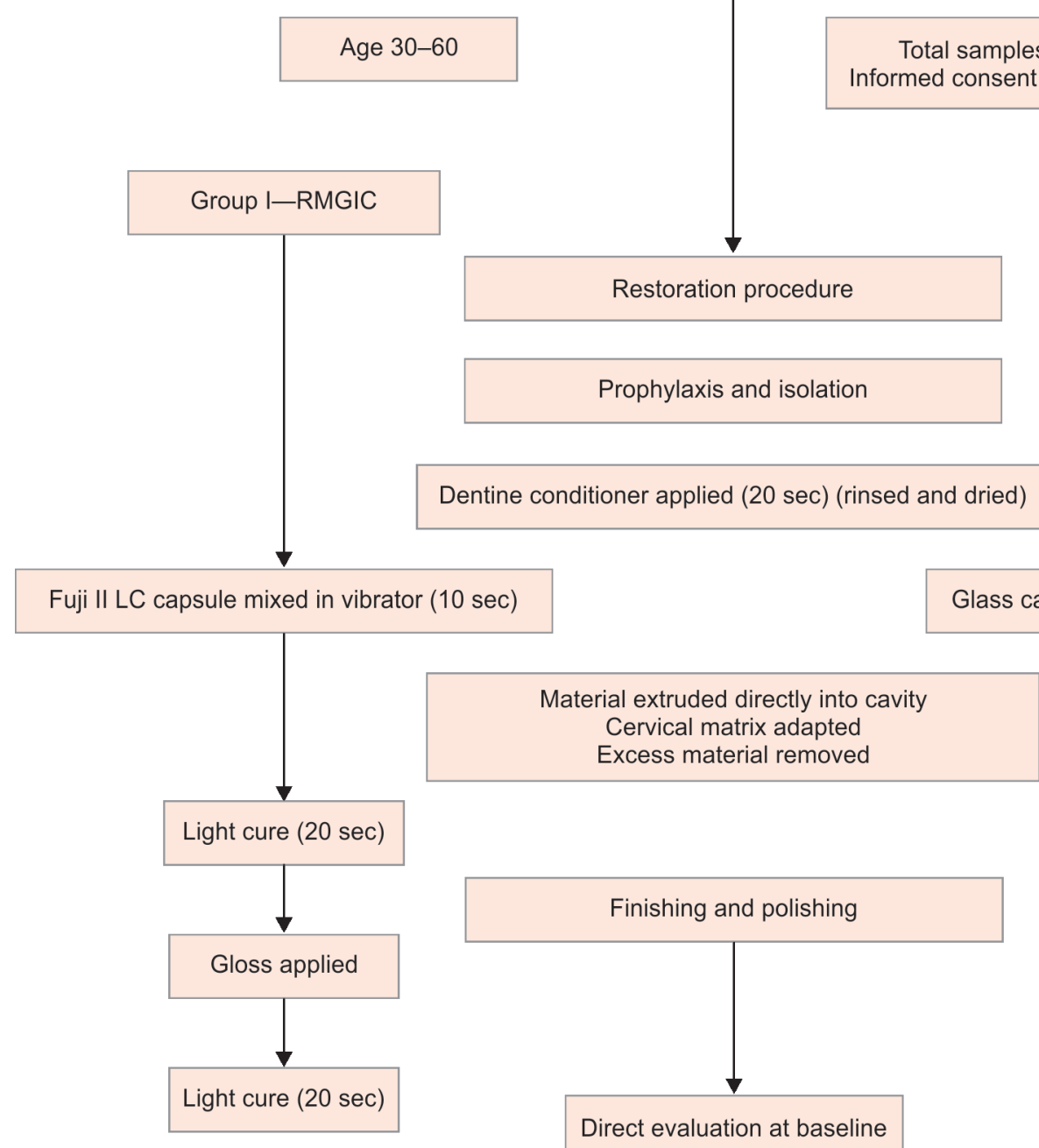

Dentine conditioner applied (20 sec) (rinsed and dried)

Total samples: 56 pairs

Informed consent randomization

Restoration procedure

Prophylaxis and isolation

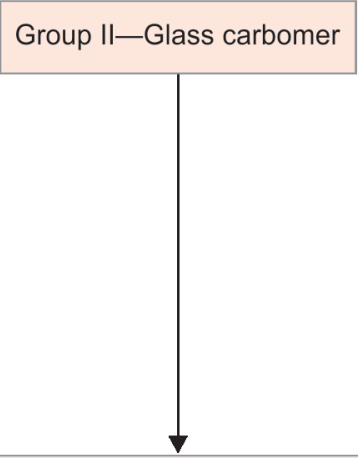

Fuji II LC capsule mixed in vibrator $(10 \mathrm{sec})$

Glass carbomer capsule mixed in vibrator $(15 \mathrm{sec})$
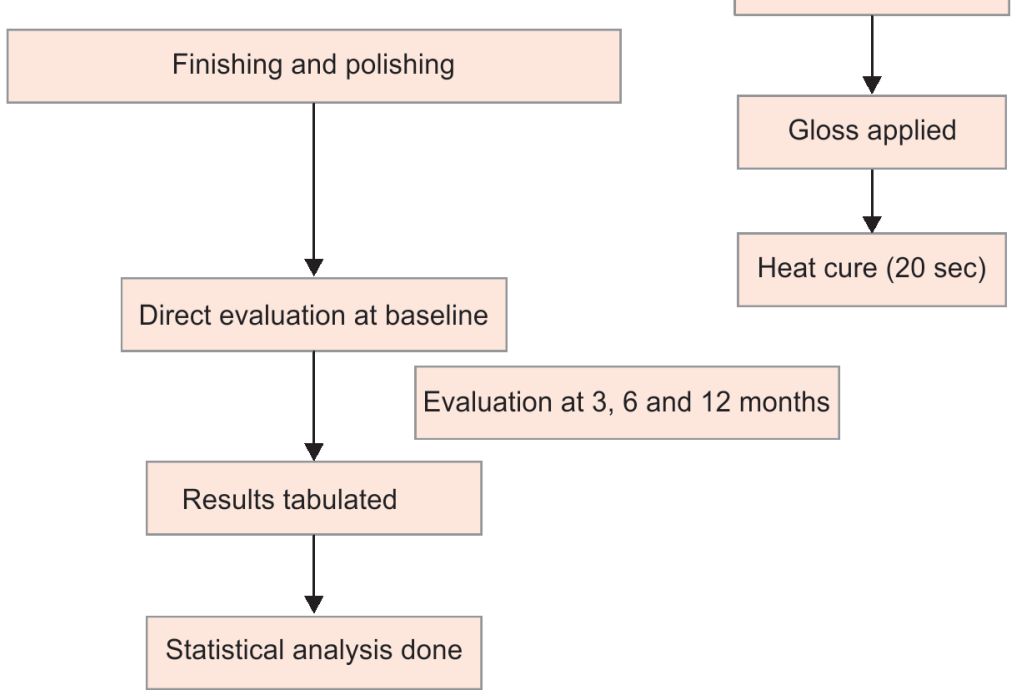

margins that lie on cementum or dentin, which is unfavorable for bonding. Age group and tooth selection were based on the prevalence of NCCLs. ${ }^{18,19}$

As the study involved the use of a heat cure unit, the buccolingual depth of the selected NCCLs was kept $\leq 2 \mathrm{~mm}$. This was measured with a calibrated probe. The use of heat increases the temperature within the cement which can lead to a rise in intrapulpal temperature. Botsali et al. found that the use of GCP glass carbomer along with a CarboLED Lamp caused high intrapulpal temperature variations $\left(5.21 \pm 0.42^{\circ} \mathrm{C}\right)$ compared to Fuji II LC $\left(3.84 \pm 0.47^{\circ} \mathrm{C}\right) .{ }^{20}$ However, according to an in vitro study done by Zach and Cohen, only when the intrapulpal temperature increased to $11.1^{\circ} \mathrm{C}$ did it result in irreversible pulpitis. ${ }^{21}$ van Duinen et al. found that applying heat for 90 seconds using GC D-light Duo increases the surface temperature to $50.2^{\circ} \mathrm{C}$ but results in only $2-3^{\circ} \mathrm{C}$ increase in temperature in the pulp space. ${ }^{22}$ This is because the thermal conductivity of glass-ionomers is low, and as found by Gavic et al., the pulpal temperature rise at $4 \mathrm{~mm}$ depths is much less than at $2 \mathrm{~mm} .{ }^{23}$ Despite this, they can conduct some heat into their bulk, and therefore can be heat-cured thus improving the rate at which they advance to their optimal physical characteristics.

Retention of glass ionomer to the tooth depends on the bond strength of the cement. In this study, a retention rate of $94.6 \%$ was 
Flowchart 2: Consort flow diagram

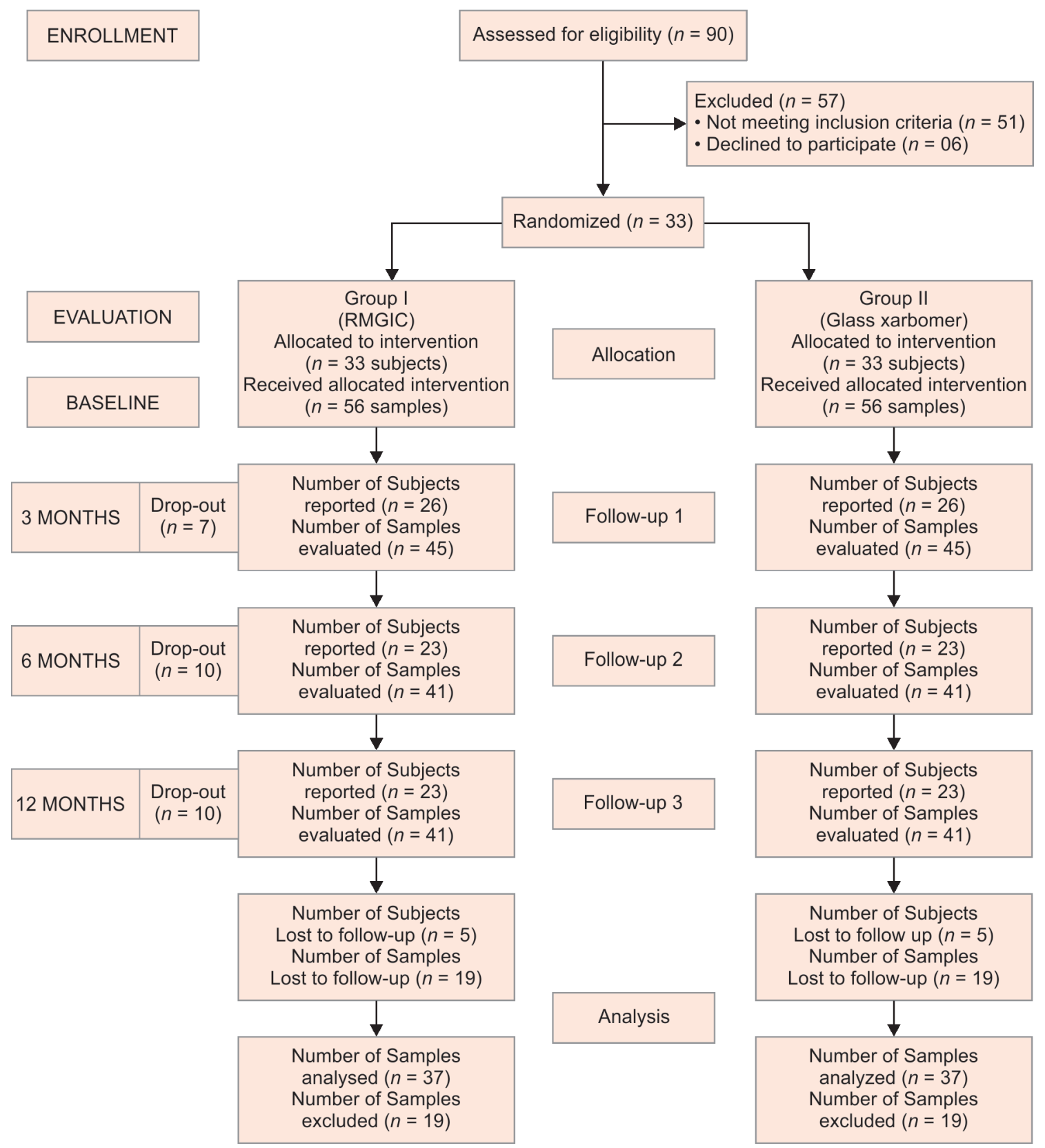

6 subjects were treated with 3 pairs of samples each, 11 subjects with 2 pairs and 16 subjects with 1 pair.

Reasons for complete dropout: Not responding to calls (4), out of town for long time interval (1)

Reasons of excluded analysis: Not present for all the evaluations due to their work-related issues; One patient could not come for 12 months evaluation because of a fractured leg. Some subjects did not come for $3 / 6$ months evaluation but reported for the other evaluations

documented for RMGIC restorations, whereas $86.5 \%$ retention was attained for carbomer.

Clinical evidence suggests that restoration loss could be due to insufficient bonding of the cement to the enamel as cervical lesions present no macro-mechanical undercuts. ${ }^{24,25}$ According to the manufacturer, glass carbomer has nano-sized powder particles that strengthen the material through an augmented particle surface in interaction with the glass-carbomer liquid resulting in stronger adhesion to the cavity wall. ${ }^{26}$ Heating at low temperatures with light emitted from a high-powered polymerization unit also improves the mechanical properties and the shear bond strength to the enamel. ${ }^{27,28}$ However, the outcomes of research done by
Olegário et al. showed a lower bond strength for carbomer than high viscosity GIC. ${ }^{5}$ Research has shown that during the chemical reaction in the glass carbomer, hydroxyapatite gets partially consumed in the setting stage. This decreases the number of accessible ions required to bond with the mineral part of the tooth, resulting in inferior bond strength. ${ }^{26}$ Dentinal water and intrinsic water of the cement also play a significant role in the bonding of glass ionomer cement to dental hard tissues because water acts as a medium in which acid-base reaction and ion exchange occur. ${ }^{29}$ However, dehydration induced by the heat and light unit used to activate the material can be another possible explanation that may affect the interface between the dentine and carbomer resulting in 
Table 1: Materials used in intervention

\begin{tabular}{|c|c|c|c|c|}
\hline S. no. & Material & Company & Country & Lot no. \\
\hline 1 & Dentin Conditioner; Composition: $10 \%$ polyacrylic acid & GC & Japan & 1511111 \\
\hline 2 & $\begin{array}{l}\text { RMGIC capsule (Fuji II LC); Composition: Aluminofluorosilicate glass, polyacrylic } \\
\text { acid, 2-hydroxyethyl methacrylate, 2,2,4-trimethyl hexamethylene dicarbonate, } \\
\text { triethylene glycol dimethacrylate }\end{array}$ & GC Corporation, Tokyo & Japan & 1503101 \\
\hline 3 & $\begin{array}{l}\text { Glass Carbomer capsule (GCP Glass Fill); Composition: Fluoroaluminosilicate } \\
\text { glass, apatite, polyacids }\end{array}$ & GCP Dental & Netherlands & 7501759 \\
\hline 4 & GCP gloss; Composition: modified polysiloxanes & GCP Dental & Netherlands & 673924 \\
\hline 5 & RMGIC Gloss (G-Coat Plus); Composition: nanofilled resin & GC & Japan & 1601061 \\
\hline
\end{tabular}

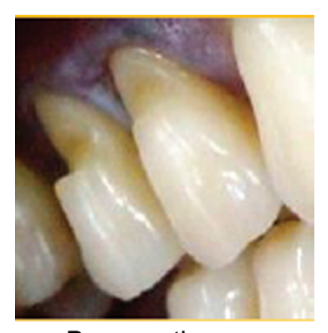

Preoperative

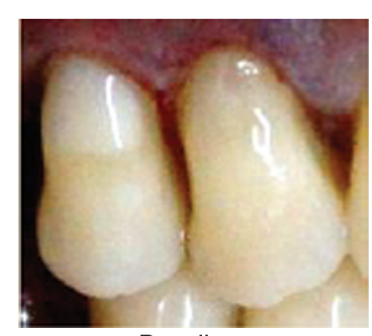

Baseline
RMGIC \#14 Carbomer \#15

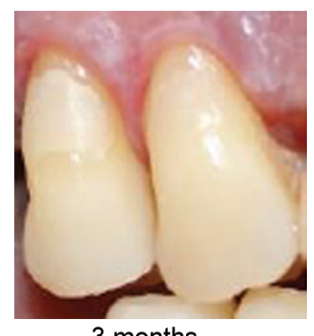

3 months

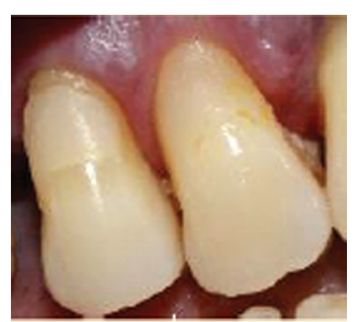

6 months

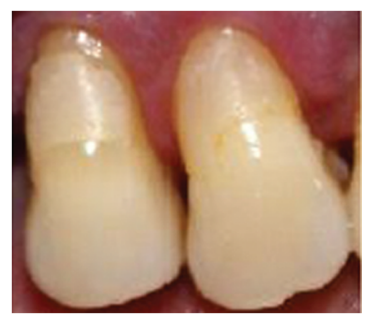

12 months

Fig. 1: Representative photographs of clinical evaluation at each evaluated time-period

poor bond strength. Chen et al. recorded retention of $41.5 \%$ with glass carbomer at 1 year which is much less than the present study. ${ }^{30}$

Another reason for retention failure is the occurrence of sclerotic dentin in NCCL, which is more resilient to adhesion than normal dentin. Mjör et al. in their study on pulp-dentin biology found that owing to the wear on the cervical and occlusal surfaces of the tooth, defense mechanisms are stimulated leading to the development of reactionary and reparative dentin that obstructs the exposed dentinal tubules. ${ }^{31}$ Thus, age becomes a component that alters the structure and composition of dentin resulting in retention failure of the restoration.

Inadequate bonding of restoration also results in marginal gaps, microleakage, and subsequently postoperative sensitivity. ${ }^{32}$ This study showed decreased sensitivity for both materials from the preoperative to the postoperative phase, but the discrepancy was not statistically significant.

The marginal integrity of the restoration is associated with the viscoelastic property of the restorative material, water sorption at the tooth-restorative interface, and unique stress patterns at the cervical margin of the tooth. ${ }^{33}$ In this study, marginal integrity significantly deteriorated for both materials after 6 months. Most marginal defects were small, either at the occlusal aspect or at the cervical margin. Resin-modified glass ionomer cement undergoes curing shrinkage due to the presence of resin resulting in volumetric changes that can create marginal gaps. ${ }^{34}$ In contrast, glass carbomer does not shrink during the polymerization process as it does not contain any solvents or resin and is as such monomer free. ${ }^{13}$ Also, since GICs are prone to water uptake and hygroscopic expansion over time it can result in lower marginal adaptation. Hence, the application of gloss provides effective surface protection and improved marginal sealing. ${ }^{12}$ However, the marginal integrity of both materials was differentially affected even in the presence of a gloss coating. This can be due to the lack of moistening effect of the surface gloss and in the case of glass carbomer combined with the dehydrating influence of the high-power light-curing unit it may have developed into a rapid decline of the tooth-material interface, leading to increased levels of leakage. Also, loss of the protective surface gloss over time can lead to defects in marginal integrity. Both Neo et al. and Gladys et al. noticed that margins that were ideal at restoration placement substantially worsened after 6 months. ${ }^{35,36}$ Hence, with regard to marginal properties, it is fair to conclude that the enamel bonding efficacy of both materials is possible to deteriorate over time.

Fracture toughness is an intrinsic property of a material that resists the transmission of a surface crack through it. At 1 year, RMGIC showed one Charlie rating whereas carbomer had four, due to bulk restoration fracture. Five carbomer restorations had a small chip but were clinically acceptable and were rated as Bravo. Olegário et al. in a 3-year randomized clinical trial of ART restorations found that the main reason for carbomer restoration failure was bulk fracture/restoration loss because of the creation of internal cracks during the setting of the material, which can get disseminated leading to restoration breakdown. ${ }^{37}$

The fracture resistance of a material also depends on its composition which includes powder particle size and powder liquid ratio. Resin-modified glass ionomer cement with an average particle size of $5.9 \mu \mathrm{m}$ and a powder liquid ratio of $3.2 \mathrm{~g} / 1.0 \mathrm{~g}$ have numerous small glass particles well-dispersed in the matrix which might be responsible for its high compressive strength. ${ }^{38}$ Carbomer with its nano-size powder particles results in reduced fracture toughness. Cracks continually run across the matrix phase or next to the matrix/particle interface. Hence, tinier particles in the material cause minimal crack deflection, resulting in a decreased fracture toughness. ${ }^{39}$ 
The surface roughness of carbomer was much less when compared to RMGIC. ${ }^{40}$ This can be because of the lower abrasion resistance of RMGIC. Resin-modified glass ionomer cement comprises glass particles in a resinous and hydrogel matrix. As the matrix degrades, the surrounding glass particles get separated from the matrix, producing a rough surface. ${ }^{41}$

On a similar note, RMGIC (78.4\%) showed greater wear than carbomer at all periods: it was statistically significant at 6 months $(p=0.0211)$ and 1 year $(p=0.0311)$. Resin-modified glass ionomer cement with low wear resistance also resulted in subsequent loss of anatomic form. ${ }^{38}$ On the other hand, carbomer having less surface roughness may be attributed to the nanoparticle size of the filler particles that result in a smoother exterior and are easier to finish and polish. ${ }^{42,43}$

The roughness on the surface of restorative materials also determines the materials' color stability. On a rough surface, light scatters, reducing restoration shine, and leading to easy deposition of stains. ${ }^{44}$ Decreasing the size of powder particles also provides excellent clinical smoothness of the surface resulting in reduced marginal staining. In this study, for both materials, the percentage of restorations showing discoloration increased with time. A Bravo rating for carbomer at baseline was given as the marginal discoloration was seen at the distal margin of the restoration, where it was difficult to access during finishing and polishing.

We also observed that upon placement $97.3 \%$ of RMGIC had an excellent color match with the surrounding tooth, which reduced to $86.5 \%$ in 1 year. This is similar to a study by Neo et al. who found the color match of RMGIC to be less than satisfactory after 18 months (48\% Alfa rating). ${ }^{35}$ This could be because of pigment absorption on the rough restorative surfaces from nutritional habits. In the case of carbomer, the color matching increased from none upon placement to $40.5 \%$ in 1 year. This suggests that even carbomer did not show color stability over time. Savas et al. found clinically unacceptable color changes in carbomer when placed in various beverages for 28 days. ${ }^{45}$

This study involved only NCCLs. Therefore, the presence of caries after placement of the restoration may be because of the oral environment, the cavity, the material, the operator's skill, or the procedure. In this study, only Carbomer showed the presence of caries (5.4\%). This is slightly more than $C$ hen et al. who reported the occurrence of caries as $2.6 \%$ following 12 months of glass carbomer material placement. ${ }^{46}$ It may be speculated that the application of surface gloss along with its heat treatment would have possibly occluded the diffusion of fluoride which is required to inhibit caries. ${ }^{43}$ However, none of the RMGIC restorations showed caries occurrence despite gloss application. This is similar to a study by Abdalla et al. who evaluated the clinical performance of RMGIC in NCCLs and found no secondary caries at the end of 1- and 2-year recalls. ${ }^{47}$ Since the marginal integrity of both the materials was differentially affected, it is possible, that oral microorganisms gained entry via gaps at the tooth restoration interface. ${ }^{48}$

Considering the limitations of this study it can be said that a 1-year clinical assessment is truly a short time to assess the longstanding clinical behavior of restorative materials.

In conclusion, though RMGIC showed superior clinical performance compared to carbomer not much statistically significant difference was seen between them. Hence, the null hypothesis was accepted that there would be no difference in the restorations done with RMGIC and those done with GCP glass carbomer cement. Glass carbomer, despite containing nano-sized powder particles and thermal setting, falls short of demonstrating 

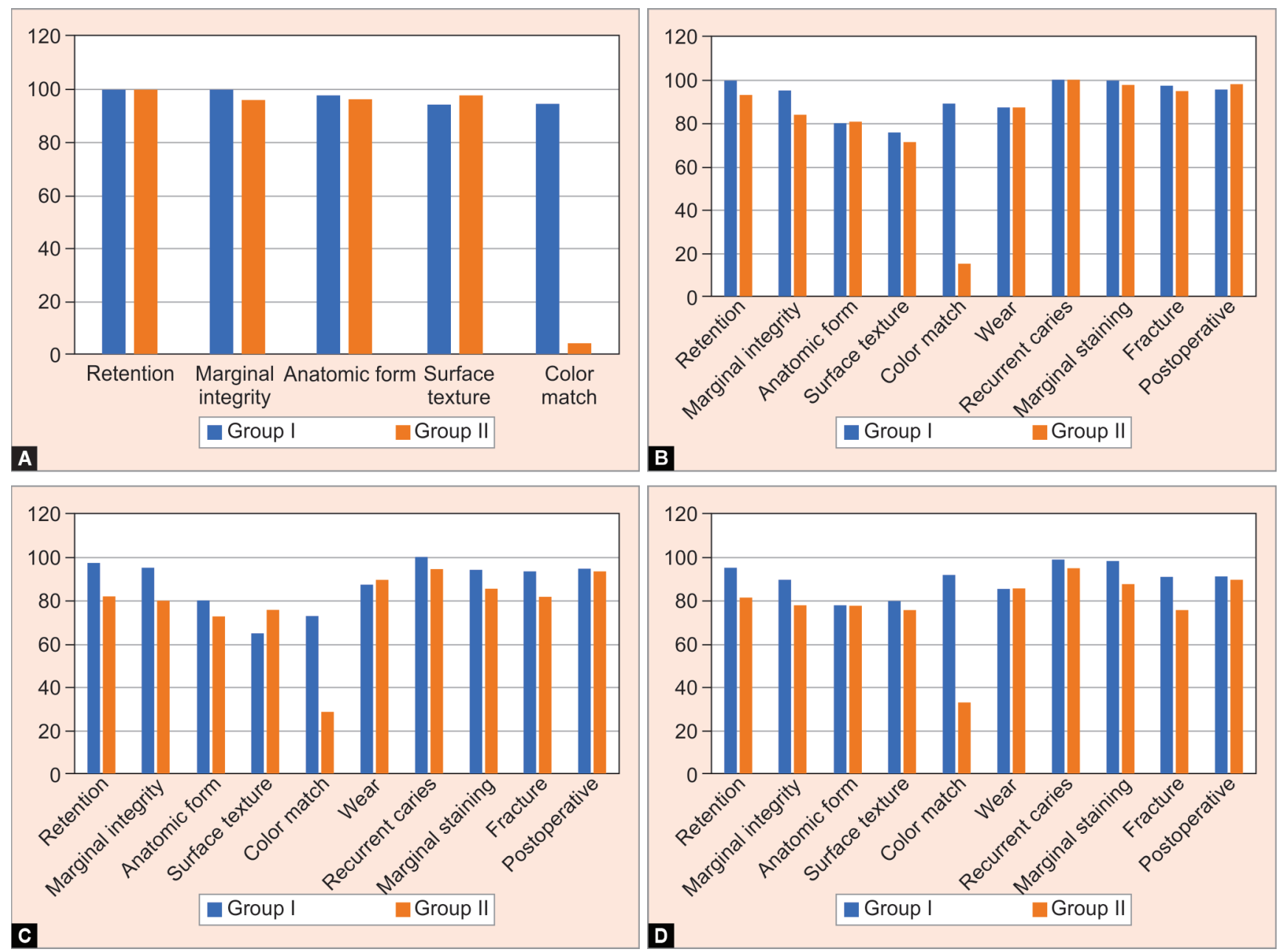

Figs 2A to D: Percentage graph of restorations that scored Alfa at baseline, 3 months, 6 months and 12 months for each parameter

acceptable clinical performance. Conclusions of this study must be validated by a more extended phase of observation.

\section{Acknowledgments}

The authors wish to thank Dr Vishnu Vardhan, Assistant Professor, Department of Biostatistics, Puducherry University and Dr Senthil Kumar Subramanian, Assistant Professor, Department of Physiology, Puducherry Institute of Medical Science, Puducherry, India for their help with statistics.

Dr Jaideep Rayapudi, Associate Professor, Department of Physiology, Puducherry Institute of Medical Science, Puducherry, India for all technical assistance and guidance.

\section{References}

1. Perdigão J, Dutra-Corrêa M, Saraceni S, Ciaramicoli M, Kiyan V. Randomized clinical trial of two resin-modified glass ionomer materials: 1- year results,. Oper Dent 2012;37(6):591-601. DOI: 10.2341/11-415-C.

2. Santiago SL, Passos VF, Vieira AHM, Navarro MFDL, Lauris JRP, Franco $E B$. Two-year clinical evaluation of resinous restorative systems in non-carious cervical lesions. Braz Dent J 2010;21(3):229-234. DOI: 10.1590/s0103-64402010000300010.

3. Van Duinen RNB, Davidson CL, De Gee AJ, Feilzer AJ. In situ transformation of glass-ionomer into an enamel-like material. Am J Dent 2004;17(4):223-227.
4. Gorseta K, Borzabadi-Farahani A, Moshaverinia A, Glavina D, Lynch E. Effect of different thermo-light polymerization on flexural strength of two glass ionomer cements and a glass carbomer cement. J Prosthet Dent 2017;118(1):102-107. DOI: 10.1016/j.prosdent.2016.09.019.

5. Olegario IC, Ferreira Prado Malagrana APV, Ha Kim SS, Hesse D, Tedesco TK, Bissoto Calvo AF, et al. Mechanical properties of highviscosity glass ionomer ement and nanoparticle glass carbomer. J Nanomater 2015. DOI: 10.1155/2015/472401.

6. Cehreli SB, Tirali RE, Yalcinkaya Z, Cehreli ZC. Microleakage of newly developed glasscarbomer cement in primary teeth. Eur J Dent 2013;7(1):15-21.

7. Gorseta K, Glavina D, Skrinjaric I. Influence of ultrasonic excitation and heat application on the microleakage of glass ionomer cements. Aust Dent J 2012;57(4):453-457. DOI: 10.1111/j.1834-7819.2012.01724.x.

8. Jyothi K, Annapurna S, Kumar AS, Venugopal P, Jayashankara C. Clinical evaluation of giomer- and resin-modified glass ionomer cement in class $\mathrm{V}$ noncarious cervical lesions: an in vivo study. J Conserv Dent 2011;14(4):409-413. DOI: 10.4103/0972-0707.87214.

9. Palmgren J. 3. Analysis of longitudinal data Diggle PJ, Heagarty $P$, Liang K-Y, Zeger SL, ed. 2nd ed., Oxford: Oxford University Press; 2002. Stat Med 2004; 23: 3399-3401.

10. Glasspoole EA, Erickson RL, Davidson CL. Effect of surface treatments on the bond strength of glass ionomers to enamel. Dent Mater 2002;18(6):454-462. DOI: 10.1016/s0109-5641(01)00068-9.

11. Bagheri R, Taha N, Azar M, Burrow M. Effect of G-Coat Plus on the mechanical properties of glass-ionomer cements. Aust Dent J 2013;58(4):448-453. DOI: 10.1111/adj.12122. 
12. Menne-Happ U, Ilie, N. Effect of gloss and heat on the mechanical behaviour of a glass carbomer cement. J Dent 2013;41(3):223-230. DOI: 10.1016/j.jdent.2012.11.005.

13. Gorseta K, Glavina D, Borzabadi-Farahani A, Van Duinen RN, Skrinjaric I, Hill RG, et al. One-year clinical evaluation of a glass carbomer fissure sealant, a preliminary study. Eur J Prosthodont Restor Dent 2014;22(2):67-71.

14. Ryge G, Snyder, M. Evaluating the clinical quality of restorations. Am Dent Assoc 1973;87(2):369. DOI: 10.14219/jada.archive.1973.0421.

15. Bayne SC, Schmalz G. Reprinting the classic article on USPHS evaluation methods for measuring the clinical research performance of restorative materials,. Clin Oral Investig 2005;9(4):1-6. DOI: 10.1007/ s00784-005-0017-0.

16. Ryge, G. Clinical criteria. Int Dent J 1980;30(4):347-358.

17. Rayapudi J, Sathyanarayanan R, Carounanidy U, John M. , [DATASET] evaluation of non-carious cervical lesions restored with resinmodified glass ionomer and glass carbomer: a single-blind randomized controlled clinical trial. Mendeley Data 2020(3):1. DOI: 10.4103/JCD.JCD_309_17. https://data.mendeley.com/ datasets/3jm55gwcg4/1.

18. Levitch LC, Bader JD, Shugars DA, Heymann HO. Non-carious cervical lesions. J Dent 1994;22(4):195-200. DOI: 10.1016/0300-5712(94)9010747.

19. El-marakby AM, Al-sabri FA, Alharbi SA, Halawani SM, Yousef MT. Noncarious cervical lesions as abfraction: etiology, diagnosis, and treatment modalities of lesions: a review article. Dentistry 2017;7(06):438. DOI: 10.4172/2161-1122.1000438.

20. Botsali MS, Ozmen B, Cortcu M, Koyuturk AE, Kahvecioglu F. Effect of new innovative restorative carbomised glass cement on intrapulpal temperature rise: an ex-vivo study. Braz Oral Res 2016;30(1):1-7. DOI: 10.1590/1807-3107BOR-2016.vol30.0067.

21. Zach L, Cohen G. Pulp response to externally applied heat. Oral Surg Oral Med Oral Pathol 1965;19(4):515-530. DOI: 10.1016/00304220(65)90015-0.

22. Nb Van Duinen R, Shahid S, Hill R, Glavina D. In-vitro study on temperature changes in the pulp chamber due to thermo-curing of glass lonomer cements,. Acta Stomatol Croat 2016;50(4):287-291. DOI: $10.15644 /$ asc50/4/1

23. Gavic L, Gorseta K, Glavina D, Czarnecka B, Nicholson JW. Heat transfer properties and thermal cure of glass-ionomer dental cements. J Mater Sci Mater Med 2015;26(10):249. DOI: 10.1007/s10856-015-5578-0.

24. Van Meerbeek B, De Munck J, Yoshida Y, Inoue S, Vargas M, Vijay $P$, et al. Adhesion to enamel and dentin: current status and future challenges. Oper Dent Washington 2003;28(3):215-235.

25. Peumans $M$, Kanumilli $P$, Demunck J, Vanlanduyt $K$, Lambrechts $P$, Vanmeerbeek $B$. Clinical effectiveness of contemporary adhesives: a systematic review of current clinical trials. Dent Mater 2005;21(9):864881. DOI: 10.1016/j.dental.2005.02.003.

26. Zainuddin N, Karpukhina N, Law RV, Hill RG. Characterisation of a remineralising glass carbomer?? ionomer cement by MAS-NMR spectroscopy. Dent Mater 2012;28(10):1051-1058. DOI: 10.1016/j. dental.2012.06.011.

27. Algera T, Kleverlaan C, Prahlandersen B, Feilzer A. The influence of environmental conditions on the material properties of setting glassionomer cements,. Dent Mater 2006;22(9):852-856. DOI: 10.1016/j. dental.2005.11.013.

28. Kleverlaan CJ, van Duinen RNB, Feilzer AJ. Mechanical properties of glass ionomer cements affected by curing methods. Dent Mater 2004;20(1):45-50. DOI: 10.1016/s0109-5641(03)00067-8.

29. Yiu CKY, Tay FR, King NM, Pashley DH, Sidhu SK, Neo JCL, et al. Interaction of glass-ionomer cements with moist dentin. J Dent Res 2004;83(4):283-289. DOI: 10.1177/154405910408300403.

30. Chen X, Du M, Fan M, Mulder J, Huysmans MC, Frencken JE. Effectiveness of two new types of sealants: retention after 2 years. Clin Oral Investig 2012;16(5):1443-1450. DOI: 10.1007/s00784-011-0633-9.
31. Mjör IA, Sveen OB, Heyeraas KJ. Pulp-dentin biology in restorative dentistry. Part 1: normal structure and physiology. Quintessence Int 2001;32(6):427-446.

32. Tolidis K, Boutsiouki C, Gerasimou P. Comparative evaluation of microleakage of a carbomer/fluoroapatite-enhanced glassionomer cement on primary teeth restorations. Eur J Paediatr Dent 2016;17(3):227-233.

33. Sidhu SK, Carrick TE, McCabe JF. Temperature mediated coefficient of dimensional change of dental tooth-colored restorative materials. Dent Mater 2004;20(5):435-440. DOI: 10.1016/j.dental.2003.02.001.

34. Attin T, Buchalla W, Kielbassa AM, Helwig E. Curing shrinkage and volumetric changes of resin-modified glass ionomer restorative materials. Dent Mater 1995;11(6):359-362. DOI: 10.1016/01095641(95)80035-2.

35. Neo J, Chew CL, Yap A, Sidhu, S. Clinical evaluation of tooth-colored materials in cervical lesions. Am J Dent 1996;9(1):15-18.

36. Gladys S, Van Meerbeek B, Lambrechts P, Vanherle G. Marginal adaptation and retention of a glass-ionomer, resin-modified glassionomers and a polyacid-modified resin composite in cervical Class-V lesions. Dent Mater 1998;14(4):294-306. DOI: 10.1016/s01095641(98)00043-8.

37. Olegário IC, Hesse D, Mendes FM, Bonifácio CC, Raggio DP. Glass carbomer and compomer for ART restorations: 3-year results of a randomized clinical trial. Clin Oral Investig 2019;23(4):1761-1770. DOI: 10.1007/s00784-018-2593-9.

38. Mitsuhashi A, Hanaoka K, Teranaka T. Fracture toughness of resinmodified glass ionomer restorative materials: effect of powder/liquid ratio and powder particle size reduction on fracture toughness,. Dent Mater 2003;19(8):747-757. DOI: 10.1016/s0109-5641(03)00022-8.

39. Brandt B, Lohbauer U, Göken M, Durst K. The influence of particle size on the mechanical properties of dental glass ionomer cements. Adv Eng Mater 2010;12(12):B684-B689. DOI: 10.1002/adem.201080067.

40. Bala O, Arisu HD, Yikilgan I, Arslan S, Gullu A. Evaluation of surface roughness and hardness of different glass ionomer cements. Eur J Dent 2012;6(1):79-86. DOI: 10.1055/s-0039-1698934.

41. Boing TF, de Geus JL, Wambier LM, Loguercio AD, Reis A, Gomes OMM. Are glass-ionomer cement restorations in cervical lesions more long- lasting than resin-based composite resins? A systematic review and meta- analysis,. J Adhes Dent 2018;20(5):435-452. DOI: 10.3290/j.jad.a41310.

42. de Paula A, Fucio S, Ambrosano G, Alonso R, Sardi J, Puppin-Rontani R. Biodegradation and abrasive wear of nano restorative materials. Oper Dent 2011;36(6):670-677. DOI: 10.2341/10-221-L.

43. de França Lopes CMC, Galvan J, Chibinski ACR, Wambier DS. Fluoride release and surface roughness of a new glass ionomer cement: glass carbomer,. Rev Odontol Da Unesp 2018;47(1):1-6. DOI: 10.1590/18072577.06717.

44. Vaid DS, Shah NC, Bilgi PS. One year comparative clinical evaluation of EQUIA with resin-modified glass ionomer and a nanohybrid composite in noncarious cervical lesions. J Conserv Dent 2015;18(6):449-452. DOI: 10.4103/0972-0707.168805.

45. Savas S, Colgecen O, Yasa B, Kucukyilmaz E. Color stability, roughness, and water sorption/solubility of glass ionomer-based restorative materials. Niger J Clin Pract 2019;22(6):824-832. DOI: 10.4103/njcp. njcp_592_18.

46. Chen X, Du MQ, Fan MW, Mulder J, Huysmans MCDNJM, Frencken $J E$. Caries-preventive effect of sealants produced with altered glassionomer materials, after 2 years. Dent Mater 2012;28(5):554-560. DOI: 10.1016/j.dental.2012.01.001.

47. Abdalla Al, Alhadainy HA, García-Godoy F. Clinical evaluation of glass ionomers and compomers in Class V carious lesions. Am J Dent 1997;10(1):18-20.

48. Sidhu SK. Clinical evaluations of resin-modified glass-ionomer restorations. Dent Mater 2010;26(1):7-12. DOI: 10.1016/j. dental.2009.08.015 